requiring hospitalization): $2 \%$ vs $0.2 \%$ and the risk presentation format: numbers only, numbers + IA, numbers + BB, and numbers + IA + BB. Route of administration, benefit, and cost were held constant. Each subject responded to a single, randomly-assigned scenario. Dependent variables included perceived riskiness, worry, global gist related to the acceptability of the $\mathrm{AE}$, and willingness to take the medication (all measured on 5-point ordinal scales). We hypothesized that the IA and $\mathrm{BB}$ formats would result in 1) lower perceived riskiness and worry, and 2) greater acceptability of the AE and willingness to take the medication in the $0.2 \%$ vs $2 \%$ scenarios. Socioeconomic status (SES) was defined based on difficulty paying for medication and education level.

Results: We mailed 1453 surveys. 465 patients completed and mailed the survey back (32\% response rate). Overall, the mean age of responders was 58.99 $(\mathrm{SD}=14.85) ; 79.7 \%$ of were female; $83.2 \%$ White and $39.1 \%$ had a low SES. There were no statistical differences in demographic or clinical characteristics across the four risk presentation formats. Mean (SD) perceived riskiness, worry, global gist, and willingness to take the medication for $2 \%$ versus $0.2 \%$ chance of the AE, by SES level, are presented in the Image.

Perceived riskiness was lower for a $0.2 \%$ versus $2 \%$ risk of the $A E$ in the numbers + IA condition in higher SES subjects. Lower SES subjects who viewed both IA and $B B$ were more worried about the $A E$ and found the $A E$ to be less acceptable in the $0.2 \%$ versus $2 \%$ condition.

\begin{tabular}{|c|c|c|c|c|c|}
\hline $\begin{array}{c}\text { Risk } \\
\text { Presentation } \\
\text { Format }\end{array}$ & & $\begin{array}{l}\text { Riskiness } \\
\text { Mean (SD) }\end{array}$ & $\begin{array}{c}\text { Worry } \\
\text { Mean (SD) }\end{array}$ & $\begin{array}{c}\text { Gist } \\
\text { Mean (SD) }\end{array}$ & $\begin{array}{l}\text { Willingness } \\
\text { Mean (SD) }\end{array}$ \\
\hline \multicolumn{6}{|l|}{ Low SES } \\
\hline \multicolumn{6}{|l|}{ Numbers Only } \\
\hline \multirow[t]{3}{*}{ AE probability } & $2 \%$ & $3.12(0.18)$ & $3.16(0.23)$ & $3.12(0.22)$ & $3.20(0.24)$ \\
\hline & $0.20 \%$ & $3.04(0.19)$ & $3.38(0.23)$ & $3.69(0.22)$ & $3.38(0.25)$ \\
\hline & p-value & 0.77 & 0.51 & 0.07 & 0.61 \\
\hline \multicolumn{6}{|l|}{ Numbers + IA } \\
\hline \multirow[t]{3}{*}{ AE probability } & $2 \%$ & $3.4(0.24)$ & $3.4(0.29)$ & $3.07(0.28)$ & $3.20(0.31)$ \\
\hline & $0.20 \%$ & $2.79(0.21)$ & $3.05(0.26)$ & $3.61(0.25)$ & $3.53(0.28)$ \\
\hline & p-value & 0.06 & 0.37 & 0.15 & 0.43 \\
\hline \multicolumn{6}{|l|}{ Numbers + BB } \\
\hline \multirow[t]{3}{*}{ AE probability } & $2 \%$ & $3.06(0.23)$ & $3.13(0.28)$ & $3.32(0.27)$ & $3.69(0.30)$ \\
\hline & $0.20 \%$ & $3.17(0.19)$ & $3.17(0.23)$ & $3.55(0.22)$ & $3.82(0.25)$ \\
\hline & $p$-value & 0.72 & 0.91 & 0.52 & 0.74 \\
\hline \multicolumn{6}{|c|}{ Numbers + $1 \mathrm{~A}+\mathrm{BB}$} \\
\hline \multirow[t]{3}{*}{ AE probability } & $2 \%$ & $2.83(0.17)$ & $2.83(0.21)$ & $3.67(0.2)$ & $4.03(0.22)$ \\
\hline & $0.20 \%$ & $3.20(0.17)$ & $3.40(0.21)$ & $2.99(0.2)$ & $3.50(0.22)$ \\
\hline & p-value & 0.12 & 0.05 & 0.02 & 0.09 \\
\hline \multicolumn{6}{|l|}{ High SES } \\
\hline \multicolumn{6}{|l|}{ Numbers Only } \\
\hline \multirow[t]{3}{*}{ AE probability } & $2 \%$ & $2.95(0.15)$ & $3.03(0.18)$ & $3.52(0.18)$ & $3.50(0.20)$ \\
\hline & $0.20 \%$ & $2.77(0.17)$ & $2.71(0.20)$ & $3.83(0.20)$ & $3.74(0.22)$ \\
\hline & p-value & 0.44 & 0.25 & 0.24 & 0.41 \\
\hline \multicolumn{6}{|l|}{ Numbers + IA } \\
\hline \multirow[t]{3}{*}{ AE probability } & $2 \%$ & $3.29(0.16)$ & $3.06(0.19)$ & $3.61(0.19)$ & $3.82(0.21)$ \\
\hline & $0.20 \%$ & $2.78(0.15)$ & $2.73(0.18)$ & $3.82(0.17)$ & $3.80(0.19)$ \\
\hline & p-value & 0.02 & 0.21 & 0.41 & 0.93 \\
\hline \multicolumn{6}{|l|}{ Numbers + BB } \\
\hline \multirow[t]{3}{*}{ AE probability } & $2 \%$ & $3.25(0.15)$ & $3.43(0.18)$ & $3.48(0.17)$ & $3.43(0.19)$ \\
\hline & $0.20 \%$ & $3.00(0.16)$ & $3.28(0.20)$ & $3.49(0.19)$ & $3.14(0.21)$ \\
\hline & p-value & 0.25 & 0.59 & 0.97 & 0.33 \\
\hline \multicolumn{6}{|c|}{ Numbers $+\mathrm{IA}+\mathrm{BB}$} \\
\hline \multirow[t]{3}{*}{ AE probability } & $2 \%$ & $2.79(0.15)$ & $2.76(0.18)$ & $3.89(0.18)$ & $4.03(0.20)$ \\
\hline & $0.20 \%$ & $3.2(0.17)$ & $3.27(0.21)$ & $3.40(0.2)$ & $3.50(0.22)$ \\
\hline & p-value & 0.07 & 0.07 & 0.07 & 0.08 \\
\hline
\end{tabular}

Conclusions: With the exception of the IA's impact on perceived riskiness among subjects with higher SES, the risk formats used did not enable subjects to correctly differentiate between a $0.2 \%$ and a $2 \%$ risk of a serious $\mathrm{AE}$. These results highlight the lack of impact of quantitative risk information on patients' risk perceptions.

Disclosure of Interest: None declared

DOI: 10.1136/annrheumdis-2017-eular.5618

\section{THU0656 ETANERCEPT BIOSIMILAR USAGE AND ASSOCIATED COST SAVINGS IN GERMANY}

K. Thakur, A. Handrich, E. Psachoulia. Biogen, Zug, Switzerland

Background: The first etanercept biosimilar was approved by the European Commission in January 2016. Of the 27,000 patients $^{*}$ estimated to be treated with etanercept biosimilar in the Europe, 5,122 patients $^{*}$ are estimated to be on the etanercept biosimilar in Germany at the end of the analysis period. Its usage in Europe may support healthcare sustainability by reducing costs, thereby relieving the burden on healthcare budgets and improving patient's ability to get the right care at the right time.

Objectives: The analysis aimed to estimate the pharmacoeconomic impact of etanercept biosimilar use in Germany between March and December 2016.

Methods: The volume of etanercept biosimilar prescribed in Germany was calculated using sell-out data from retail pharmacies to patients sourced from INSIGHT Health. For this analysis, only the pre-filled syringe (PFS) and pre-filled pen (PFP) presentations of $50 \mathrm{mg}$ etanercept were considered. The biosimilar volume share was calculated by dividing the total etanercept biosimilar $50 \mathrm{mg}$ units prescribed by total etanercept $50 \mathrm{mg}$ units prescribed. The cost savings realized through the use of the biosimilar was calculated using the INSIGHT Health volume data and the pharmacies selling price (source: Lauertaxe) of the etanercept reference product and the etanercept biosimilar. (Note: volume, volume share, patient and price data will be updated at time of presentation to reflect most current impact of etanercept biosimilars use).

Results: Based on 5,122 patients currently estimated to be treated with etanercept biosimilar (volume share of $21.4 \%$ in Dec 2016) in Germany and on the price differential between etanercept biosimilar and the reference product, a total cost saving of 8.8 million EUR was realized during the analysis period. Assuming these patients remain on etanercept biosimilar treatment, a total savings of 21.1 million EUR ${ }^{* *}$ can be returned annually to the healthcare system, compared to using only the reference product. This annual cost savings could be utilized to provide treatment to additional 1,208 patients with etanercept biosimilar.

Table 1. No. of $50 \mathrm{mg}$ Pen/PFS etanercept prescribed: March-Dec 16

\begin{tabular}{lccc}
\hline Product & Pen & PFS & Total \\
\hline Reference product & 318,317 & 580,563 & 898,880 \\
Biosimilar & 71,408 & 40,658 & 112,066 \\
\hline
\end{tabular}

\section{—Cumulative cost saing —Monthly etanercept biosimilar volume share}

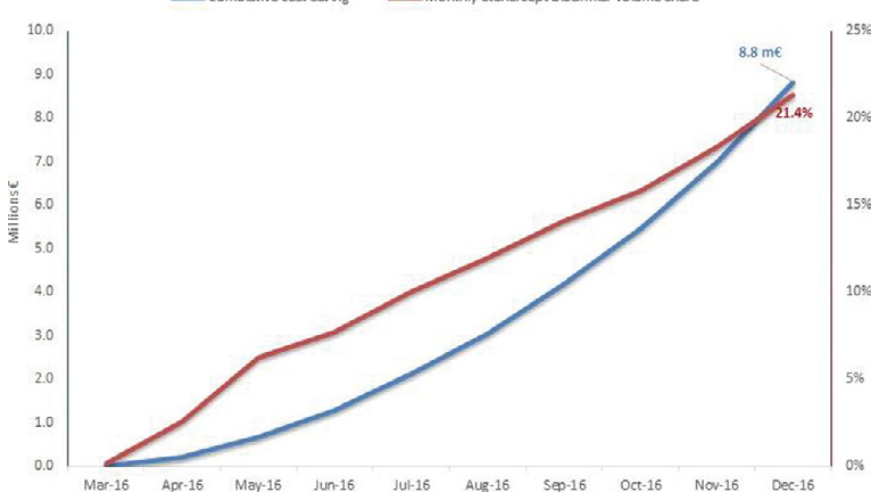

Conclusions: Experience with etanercept biosimilar has been growing in Germany, as reflected by the growing market share. Based on the current number of patients treated with etanercept biosimilar, savings of 21.1 million EUR are projected to be returned to the health system in Germany annually. The economic burden associated with etanercept treatment is expected to decrease further with an increase in market share for the etanercept biosimilar. These savings can have a significant impact on broadening patient access to biologic treatment in Germany.

References:

[1] http://www.ema.europa.eu/.

[2] INSIGHT Health GmbH \& Co.KG.

[3] WHO ATC/DDD classification (final) for etanercept in: WHO Drug Information Vol 15, No 2, 2001.

Disclosure of Interest: K. Thakur Shareholder of: Biogen, Grant/research support from: Biogen, Employee of: Biogen, A. Handrich Shareholder of: Biogen, Grant/research support from: Biogen, Employee of: Biogen, E. Psachoulia Shareholder of: Biogen, Grant/research support from: Biogen, Employee of: Biogen

DOI: 10.1136/annrheumdis-2017-eular.3380

\section{THU0657 A TELE-HEALTH FOLLOW-UP STRATEGY FOR TIGHT CONTROL OF DISEASE ACTIVITY IN RHEUMATOID ARTHRITIS: RESULTS OF THE NON-INFERIORITY RANDOMISED CONTROLLED TRAIL (THE TERA STUDY)}

A. Thurah ${ }^{1,2}$, K. Steengaard-Pedersen ${ }^{1,2}$, M. Axelsen ${ }^{3}$, U. Fredberg ${ }^{3,4}$, L.M.V. Schougaard $^{5}$, N.H.I. Hjøllund ${ }^{5,6}$, M. Pfeiffer-Jensen ${ }^{1,2}$, T.B. Laurberg ${ }^{1}$, K. Lomborg 6,7, T. Maribo 8,9 . ${ }^{1}$ Department of Rheumatology, Aarhus University Hospital; ${ }^{2}$ Clinical Medicine, Aarhus University, Aarhus; ${ }^{3}$ Diagnostic Centre, Silkeborg Regional Hospital, Silkeborg; ${ }^{4}$ Department of Rheumatology, Odense University Hospital, Odense, ${ }^{5}$ WestChronic, Department of Occupational Medicine, University Clinic, Health, Aarhus University, Herning: ${ }^{6}$ Clinical Epidemiology, Aarhus University; ${ }^{7}$ The Research Programme in Patient Involvement, Aarhus University Hospital; ${ }^{8}$ Defactum, Central Denmark Region;

${ }^{9}$ Department of Public Health, Section for Clinical Social Medicine and Rehabilitation, Aarhus University, Aarhus, Denmark

Background: Despite the increased prevalence of rheumatoid arthritis (RA) in recent years, no studies have yet investigated the effect of monitoring disease activity through a standardized tele-health strategy in patients with RA (1).

Objectives: To test the effect of patient-reported outcome (PRO) based telehealth follow-up for tight control of disease activity in patients with RA, and the differences between tele-health follow-up performed by rheumatologists or rheumatology nurses. 